SHORT REPORT

\title{
Non-participation in sports injury research: why football players choose not to be involved
}

\author{
R Braham, C Finch, P McCrory
}

Br J Sports Med 2004;38:238-239. doi: 10.1136/bjsm.2002.003525

\begin{abstract}
Objective: To ascertain the reasons behind players not participating in a sports safety research project.

Methods: During the preseason, 10 Australian football clubs volunteered 23 teams to participate in a protective equipment randomised controlled trial, the Australian Football Injury Prevention Project (AFIPP). All players from these teams were invited to participate. Players who did not agree to participate in AFIPP were surveyed about their reasons for non-involvement.

Results: 110 football players (response rate 63.6\%) completed the non-responder survey and cited the two main reasons behind non-involvement in the project as "I did not know about the project" (39.4\%) and "I was not at training when the research team visited" (36.5\%).

Conclusions and implications: Preseason may not be the best time for maximal player recruitment in community based sports safety research. Enhanced communication between researchers and players at community level football clubs during the recruitment phase is likely to improve response rates.
\end{abstract}

M ost randomised controlled trials (RCTs) depend on the willingness of participants to be involved. ${ }^{1}$ If the study results are to be generalised, it is important that there is no recruitment bias. ${ }^{2}$ With an increasing emphasis on evaluating sports injury interventions, the issue of how to recruit participants for such studies is becoming more important. In RCTs, players are randomly allocated to intervention or control arms and injury rates compared across the different groups. ${ }^{3}$ Selection bias can be a concern if participants volunteer for the study on the basis of which intervention/control group they are assigned to. Ideally, groups or individuals should be recruited into RCTs before randomisation occurs to eliminate any bias associated with prior knowledge about intervention arm allocation. ${ }^{1}$ In studies requiring participants to volunteer before randomisation, the response rate may be compromised if people do not want to volunteer if they have no control over the assignment into intervention arms. For example, evaluations of protective equipment for footballers may be biased if players with a negative attitude towards such equipment choose not to volunteer.

This study identified reasons why footballers did not participate in an RCT of protective equipment. Such knowledge is crucial for the development of effective player recruitment strategies for injury prevention research.

\section{METHODS}

The Australian Football Injury Prevention Project (AFIPP) was an RCT to assess the effectiveness of headgear and mouthguards in community level footballers. A cluster randomisation process ${ }^{2}$ allocated 23 teams from 10 Australian rules football clubs in metropolitan Melbourne, Victoria to one of four intervention arms: (1) headgear; (2) custom mouthguards; (3) headgear and mouthguards, and (4) control.

All players from the 23 teams were invited to participate in AFIPP after team randomisation by the researcher who attended team training sessions. Recruitment for AFIPP took place during the 2001 preseason (February to March). A player list for each club was reviewed mid-season by the researcher and AFIPP players were identified. All players who were not involved in the main study were approached midseason to complete a survey of their protective equipment practices and reasons for not participating in AFIPP.

The survey was developed based on a pilot survey ${ }^{4}$ and supplemented with additional questions specifically related to non-participation in AFIPP. The survey asked about demographics, playing and injury history, attitudes towards protective equipment (five point Likert scale from strongly agree to strongly disagree) and two reasons for not participating in AFIPP. All data were double entered into SPSS version 11.0 (SPSS Inc, Chicago, IL, USA) and analysed using descriptive statistics, $t$ tests, and $\chi^{2}$ tests. Ethics approval was obtained from the Deakin University Human Research Ethics Committee.

\section{RESULTS}

A total of 110 players from the 23 teams approached to participate in the AFIPP were surveyed. The 110 players constitute $63.3 \%$ of all non-AFIPP participants from the 23 teams.

Non-AFIPP players were significantly older than AFIPP players (24.2 years $v 22.3$ years, $t=-3.110, \mathrm{p}=0.02$ ). There were no other significant differences in demographic details, injury history, or protective equipment use between responders and non-responders.

The six most commonly reported reasons (accounting for $75.6 \%$ of all stated reasons) for non-participation in AFIPP are listed in table 1 . Over two thirds of responses were attributed to either not knowing about the project or not being at training on the night that the research team visited.

Significantly more players with a head/dental injury history, than those without, reported not participating in AFIPP because of worry that they would be targeted by other players. Players who did not usually wear a mouthguard during training and/or games were also significantly more likely to report not participating in AFIPP because they already had protective equipment. There were no other significant associations between non-participation in AFIPP and self reported use of protective equipment or previous injury history.

Abbreviations: AFIPP, Australian Football Injury Prevention Project; $\mathrm{RCT}$, randomised controlled trial 
Table 1 Six most frequently reported reasons behind players' non-involvement in AFIPP $(n=104)$

\begin{tabular}{|c|c|}
\hline $\begin{array}{l}\text { Reason for not participating in } \\
\text { the AFIPP } \text { project }^{*}\end{array}$ & $\begin{array}{l}\text { Proportion of } \\
\text { players }(\%)\end{array}$ \\
\hline I did not know about the project & 39.4 \\
\hline $\begin{array}{l}\text { I was not at training when the research team visited } \\
\text { my club }\end{array}$ & 36.5 \\
\hline I already have headgear/mouthguard & $23.1 \dagger$ \\
\hline I did not want to & 14.4 \\
\hline Protective equipment restricts my playing ability & 14.4 \\
\hline I was worried I would be targeted by other players & $10.6 \ddagger$ \\
\hline \multicolumn{2}{|c|}{$\begin{array}{l}\text { *Wording as per questionnaire. } \\
\text { †Significantly different in players who usually wore/did not wear a } \\
\text { mouthguard ( } 32.3 \% \text { v } 5.6 \%, 95 \% \mathrm{Cl} \text { for difference } 18.2 \text { to } 35.2) \\
\text { †Significantly different in players with and without a previous injury } \\
\text { history }(23.8 \% \text { v } 7.3 \%, 95 \% \mathrm{Cl} \text { for difference } 9.3 \text { to } 23.6)\end{array}$} \\
\hline
\end{tabular}

\section{DISCUSSION}

Recruiting players from community sporting teams is challenging because of the voluntary nature of the activities and the non-compulsory training sessions, especially during preseason. However, studies of the effectiveness of injury counter measures depend on the recruitment of adequate numbers and representative samples of players. Therefore, it is important to establish why players choose not to participate in sports safety research to enhance the development of optimal recruitment strategies.

Significantly more players who had sustained a head and/ or dental injury in the past 12 months reported their reason for not participating in the study as "I was worried that I would be targeted by other players". It is possible that this could be attributed to players with negative past experiences with protective equipment preferring to play without it.

Players who did not usually wear a mouthguard during training and/or games were significantly more likely to report not participating in the AFIPP because they already had protective equipment. Although this appears contrary, such players may have felt that they did not need to join the trial to receive protective equipment.

It seems that players are interested in participation in research with the majority reporting that their non-participation was due to non-attendance at training, or miscommunication. This is an encouraging result as these players may have registered for the study had they been adequately informed about it, highlighting the issue of clear communication strategies to maximise recruitment.

This study highlights two main issues with community level football player recruitment: communication and timing. Both are likely to be associated with player recruitment during preseason. This coincides-in Australia-with the cricket season which, in turn, may lead to a conflict of interest for those players wanting to participate in both sports. In community sport, player registrations are usually permitted up until mid-season because there can be a lack of player numbers and mid-season recruits are a welcome addition. From a research perspective, player recruitment needs to be completed well before mid-season to enable data collection throughout an entire playing season. It would also seem that there may have been a lack of communication from management and coaching staff to the players, with one third attributing their non-participation to not knowing about the project. Communication from football personnel (coaches and team managers) was the primary way that information about AFIPP was conveyed to the players. If this channel of communication was flawed, then this may have hindered the recruitment process.

In summary, our results provide encouraging information for sports safety research. It appears that the reason players choose not to participate in research is not because they are skeptical about the effectiveness of protective equipment or dislike it: rather they missed the opportunity to be involved because of an absence during the recruitment phase or they were uninformed.

Logistically, preseason recruitment is ideal to allow for adequate study preparation time. Recruitment involving community sporting teams should take place as close to the start of the playing season as is possible to minimise nonparticipation due to non-attendance at preseason training because of other sporting commitments. Similar studies may need to monitor injuries for more than one season or increase the player/study size, to eliminate the need for preseason recruitment. Future studies should incorporate information sessions where a project member speaks to the entire team about the project - a prerequisite of nomination to improve communication between the research team and the players.

\section{ACKNOWLEDGEMENTS}

AFIPP was funded by the Victorian Health Promotion Foundation. The Eastern Football League and the clubs, teams, and players are thanked for their contribution to this project.

\section{Authors' affiliations}

R Braham, Sports Injury Prevention Research Unit, Monash University C Finch, University of New South Wales, NSW Injury Risk Management Research Centre

P McCrory, Brain Research Institute and Centre for Sports Medicine Research and Education, University of Melbourne

Correspondence to: Associate Professor Caroline Finch, University of New South Wales, NSW Injury Risk Management Research Centre, Sydney 2052, Australia; c.finch@unsw.edu.au

Accepted 29 March 2003

\section{REFERENCES}

1 Beaglehole R, Bonita R, Kjellstrom T. Basic Epidemiology 1993.

2 Murray DM. Design and analysis of group-randomized trials. New York: Oxford University Press, 1998.

3 Caine C, Caine D, Lindner K. The Epidemiologic Approach to Sports Injuries. In: Caine DJ, Caine CG, Lindner KJ, eds. Epidemiology of Sports Injuries. Champaign, IL: Human Kinetics Publishers, 1996:1-13.

4 Finch C, Mclntosh A, McCrory P, et al. A pilot study of the attitudes of Australian rules footballers towards protective headgear. J Sci Med Sport 2003;6:505-11. 